\title{
Experimental and Numerical Research on Steel Plate Shear Wall with Infill Plate Connected to Beam Only
}

\author{
Amirhosein Raisszadeh ${ }^{\mathrm{a}}$, Ardeshir Deylami ${ }^{\mathrm{a}}$, Alireza Rahai a \\ ${ }^{a}$ Dept. of Civil \& Environmental Engineering, Amirkabir University of Technology, Tehran, Iran.
}

Received 17 January 2018; Accepted 14 March 2018

\begin{abstract}
Steel plate shear walls consist of thin infill steel plates attached to beams, called (horizontal boundary elements, HBEs), and columns (vertical boundary elements, VBEs) in structural steel frames. The thin unstiffened web plates are expected to buckle in shear at low load levels and develop tension field action, providing ductility and energy dissipation through tension yielding of the web plate. HBEs are designed for stiffness and strength requirements and are expected to anchor the tension field formation in the web plates. VBEs are designed for yielding of web plates and plastic hinge formation at the ends of the HBEs. This design approach may result in very large demand on boundary frame members, especially VBEs in most cases. Several methods such as using LYP, perforating the infill plate and omitting connection of infill plate to columns have been proposed to reduce the moment and axial force demands on the VBEs. Study the behavior of steel plate shear walls omitting the connection of infill plate and columns is the main purpose of this research. A classic analysis base on PFI method along with quasi static cyclic experimental study has been performed in order to investigate the behavior of such a system. The results of the experimental study are used to verify numerical models. Behaviors of proposed system (overall capacity and initial stiffness) were compared with those of the conventional SPSWs. Results show that both parameters are reduced in comparison to the conventional SPSWs.
\end{abstract}

Keywords: SPSW; Hystertic Behavior; Ultimate Capacity; Initial Stiffness.

\section{Introduction}

Steel plate shear walls (SPSW) are lateral load resisting systems which are used in regions of high seismicity. A typical SPSW consists of infill steel plates connected to the beams, known as the horizontal boundary elements (HBEs); and to the columns, as the vertical boundary elements (VBEs). The infill plate connected to the surrounding beams and columns, buckles in shear at low lateral loads and develop a diagonal tension field that induces sever stresses on the surrounding frame members. From the numerous investigations conducted worldwide, it has been shown that SPSWs have many advantages such as high initial stiffness and ultimate shear strength, substantial ductility, fast construction, reduction of seismic mass and increased useable floor plan. The overall building cost of SPSW structures is also shown to be reduced in comparison with other lateral load resisting systems [1-8].

Many previous experimental and analytical studies have shown that using of web plates with minimum available thickness larger than required for resisting specified lateral loads may also result in excessive design forces to the HBEs and VBEs, thus increasing their size. Column flexural demands result from the development of the tension field in the infill plate (pull-in forces) and from the frame action of the boundary moment frame. Column axial demands result primarily from resisting the overturning moment that can be large for multi-story SPSWs, Column axial demands is also the result of infill plate pull in forces vertical component. As a result, there exists concern about VBEs high demand that

\footnotetext{
* Corresponding author: deylamia@aut.ac.ir

dol http://dx.doi.org/10.28991/cej-0309113
}

$>$ This is an open access article under the CC-BY license (https://creativecommons.org/licenses/by/4.0/).

(C) Authors retain all copyrights. 
may prevent further widespread acceptance of this system.

To reduce column demands in SPSWs, some researchers have investigated the use of low yield point steel for the infill plate, reduced beam sections at beam-to-column connections, and strategic placement of holes in the infill panels [9 -11]. Some other researchers reduced the column forces using semi supported steel plate shear walls, which the infill plate is connected to secondary columns that are placed to anchor the plate forces [12,13]. A number of researchers used coupling beams to reduce overturning forces [14-16]. Other researchers disconnected steel plate from columns to eliminate pull-in forces [16-20]. The contribution of the infill plate connected only to the beams of the boundary frame was found to be significant in terms of energy dissipation, initial stiffness and lateral strength [14]. Park [13] reported that SPSWs with infill plates connected only to the beams exhibited an excellent deformation capacity equivalent to that of the walls with fully connected infill plates, although its load-carrying capacity and energy dissipation capacity decreased. Shekasteband et al. [20] tested four 1:6 scaled one-story Experimental SPSW models with hinge type connections in boundaries at four corners, they reported that using frame connection for plates increases the energy dissipation, shear strength and elastic stiffness by up to $150 \%, 200 \%$ and $110 \%$ on average, respectively compared to those of beams-only connected walls.

Limited performed experimental studies on such a system illustrated that these systems have considerable shear strength and can be used to separate the shear walls from the main columns. So the performance of this system which the infill plate is detached from columns, called DSPSW, in a moment frame is the main aim of this research. In this research first capacity and stiffness of this system is derived through theoretical study and the result is compared to a series of experimental and numerical models. Also the PFI theory which is presented by Sabouri et al. [21] is discussed for DSPSWs and related equations are presented.

\section{Estimation of the Structure Properties}

Figure 1 present a schematic view of the proposed system. As it is shown, in this system tension field is forming partially.

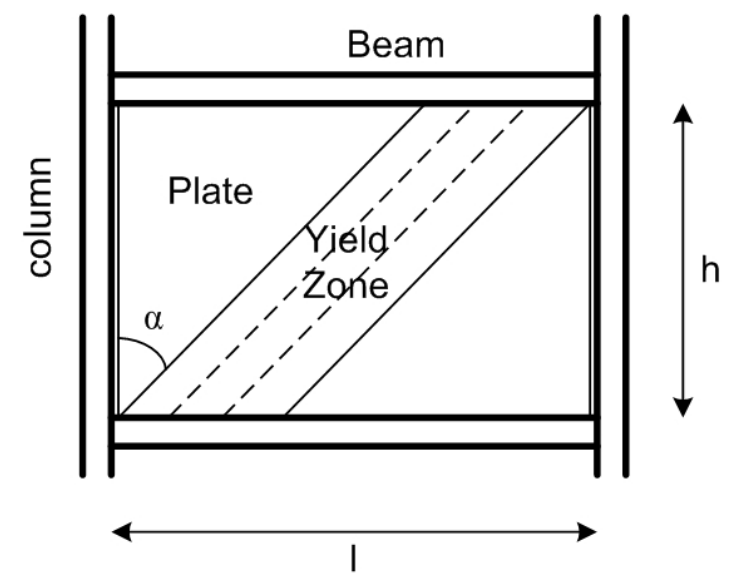

Figure 1. Partial tension field in DSPSW

The capacity of the SPSW is sum of the contribution of infill plate and the moment resisting frame capacity :

$V_{u}=V_{p}+V_{f}$

The infill plate capacity in DSPSWs can be achieved using Equation 2:

$V_{p}=[\operatorname{lcos}(\alpha)-h \sin (\alpha)] \sin (\alpha) \cdot t \cdot \sigma_{y}$

In Equations (2) $l$ is the infill plate width and $h$ is the infill plate height as shown in figure $1, t$ is the infill plate thickness, $\sigma_{y}$ is the infill plate yield stress and $\alpha$ is tension field angle respect to vertical line.

Using the principle of the least work, tension field angle is calculated as:

$$
\alpha=\frac{1}{2} \tan ^{-1}\left(\frac{l}{h}\right)
$$

Which depends on just plate geometry. The moment frame capacity is dependent on the location of plastic hinges. In case of a frame with rigid beams it can be calculated from following Equation:

$$
V_{f}=\frac{4 M_{f p}}{h}
$$

Where, $\mathrm{M}_{\mathrm{fp}}$ is the plastic moment of the column [22]. 
The other parameter which is important in structure behavior is the structure stiffness. As Saburi-Ghomi and Asad Sajjadi explained in PFI method the stiffness in SPSWs is consisted of frame stiffness and infill plate stiffness [22].

The frame stiffness is function of beam and column stiffness which for a frame with almost rigid beams it can be calculated as:

$$
K_{f}=\frac{24 E_{f} I_{f}}{h^{3}}
$$

Where $I_{f}$ and $E_{f}$ are moment of inertia of columns and column elasticity modulus.

The infill plate stiffness can be calculated as following Equation:

$$
K_{p}=\frac{[l-h \cdot \tan (\alpha)]}{4 h} . \text { E.t. } \sin ^{2}(2 \alpha)
$$

To control the above equations a series of experimental study is done.

\section{Test Program}

\subsection{Design of Specimens and Setup}

Three one-third scale specimens (SP1, SP2 and SP3) were designed considering laboratory limitations. The first specimen, SP1 was designed having infill plate attached only to the beams of its boundary frame, while the second specimen SP2 was considered with the infill plate connecting both beams and columns of the frame. SP3 was considered without the infill plate to investigate the plate effect on SP1 and SP2. SP1 and SP2 specimens are represented in Figure2 and 3 , respectively.

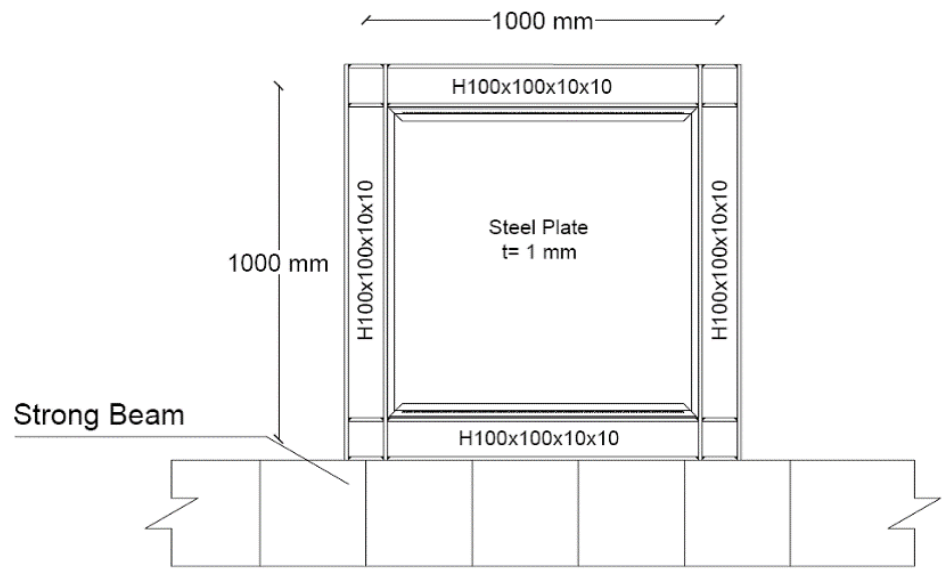

Figure 2. Specimen SP1

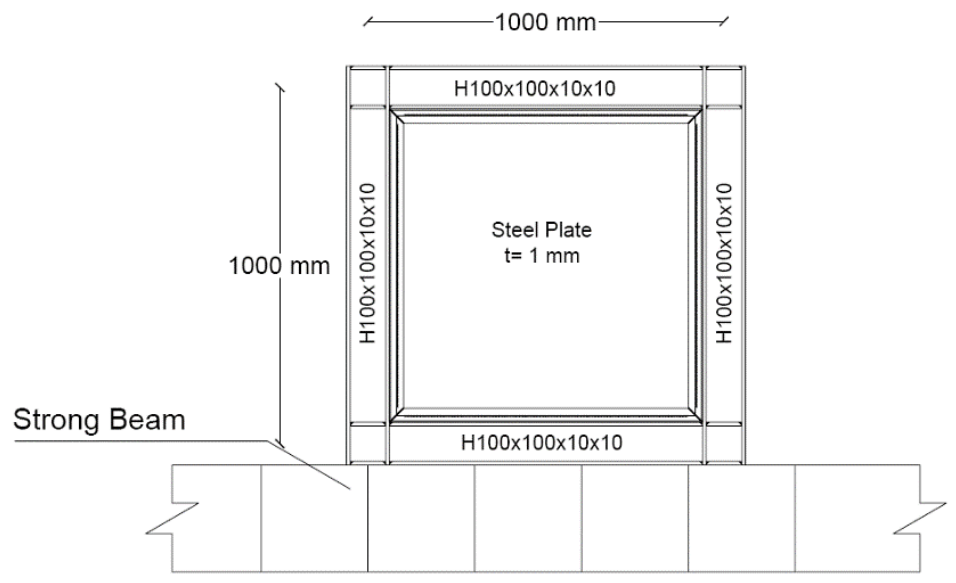

Figure 3. Specimen SP2

The specimen's dimensions and other characteristics of the specimens are summarized in Table 1 . The boundary frame members are of ST37 steel. Both columns and beams have the same built up section $H=100 \times 100 \times 10 \times 10$ (web depth $\times$ flange width $\times$ web thickness $\times$ flange thickness). The sections considered to satisfy the seismic provisions for structural steel buildings [23] width-thickness limitations, and withstand large pull in forces from the 
infill plate. Fully restrained moment connections were used at all beam to column joints. The beam flanges were rigidly connected to the columns by full-penetration groove welds. The beam web was connected to columns by fillet weld (Figure 4). To avoid flange local bending in columns, continuity plates were used at the connection. The infill plate in specimens SP1 and SP2 was welded to the boundary frame members using $40 \times 40 \times 4 \mathrm{~mm}$ angles as fish plates. The connection of infill plate to angles was provided using TIG welding. The angles were connected to beams and columns (specimen SP1 and SP2) by fillet welding (Figure 4).

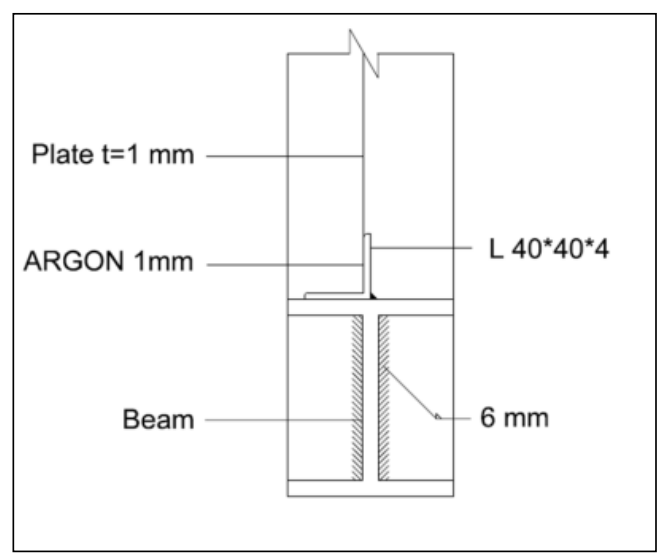

Figure 4. Detail of connection

Table 1. Specimen properties

\begin{tabular}{ccccc}
\hline Specimen & Plate thickness & Panel aspect ratio & Plate slenderness ratio & Connection detail of infill plate \\
\hline SP1 & $1 \mathrm{~mm}$ & 1 & $1 / 880$ & Only to beams \\
SP2 & $1 \mathrm{~mm}$ & 1 & $1 / 880$ & Both to beams and columns \\
SP3 & - & 1 & - & - \\
\hline
\end{tabular}

The materials used in the specimens were tested using ASTM E8 standard. The typical average stress-strain curves of the materials is shown in Figure 5. Four coupons were tested for each material. The average results of the coupon tests are presented in Table 2.

Table 2. Material properties

\begin{tabular}{ccccc}
\hline Member & Thickness $(\mathbf{m m})$ & Young modulus(MPa) & Yield stress(MPa) & Ultimate stress(MPa) \\
\hline Frame & 10 & 194000 & 280 & 383 \\
Infill plate & 1 & 185000 & 140 & 312 \\
\hline
\end{tabular}

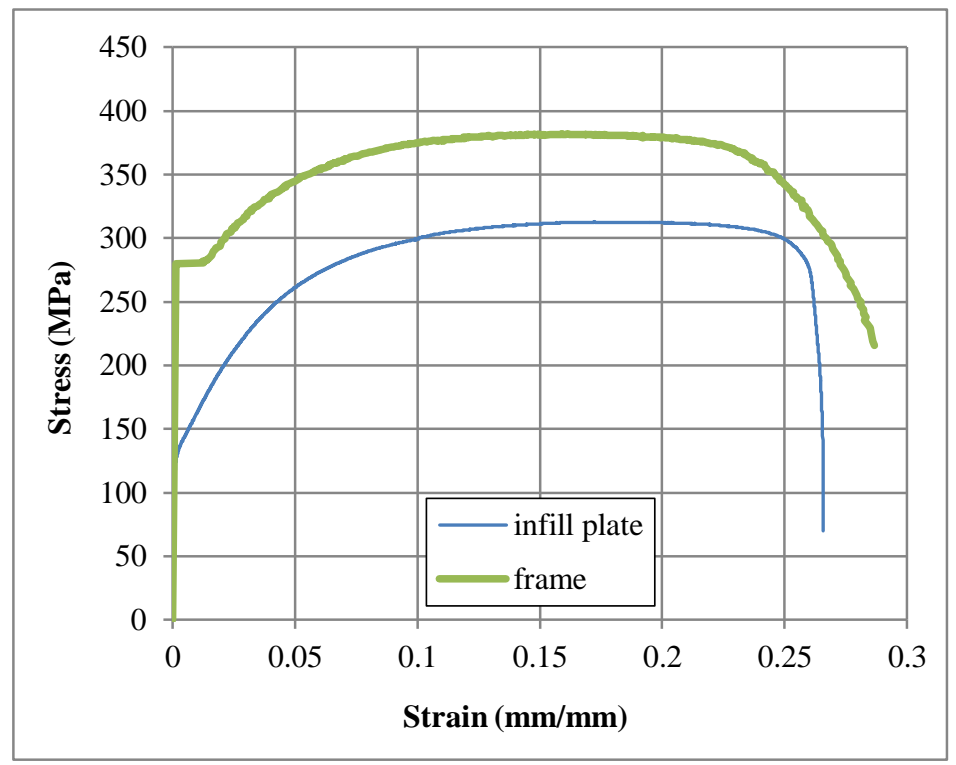

Figure 5. Stress-strain curves of materials 


\subsection{Test Results}

The loading protocol of ATC 24 was followed which is shown in Figure 6.

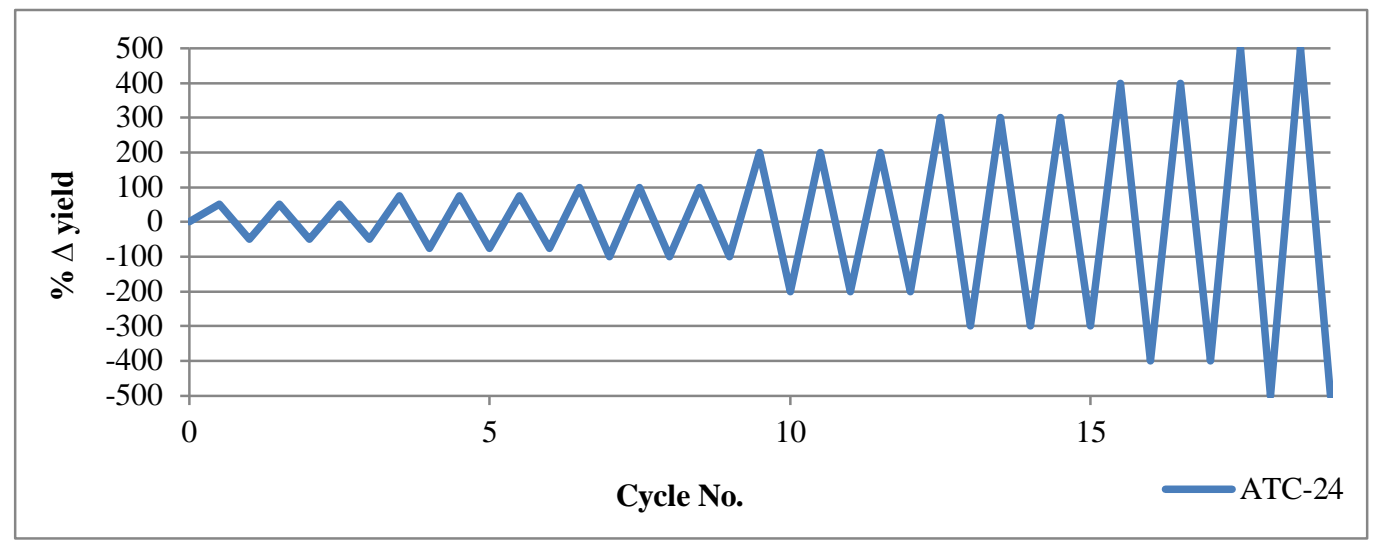

Figure 6. ATC-24 Loading Protocol

Experimental results are described using observations made during the tests and interpretation of the experimental data.

\subsubsection{Specimen SP1}

Cyclic response of specimen SP1 is shown in Figure 7. The specimen behaved elastically during the first 9 cycles of loading. After this point, some insignificant nonlinear behaviour was observed. This nonlinearity occurred due to local buckling of the infill plate. At $0.6 \%$ drift and a base shear of $102 \mathrm{kN}$ during cycle 12 the nonlinear behaviour became significant.

During cycles $20-21$ (1.8\% drift) a small tear was observed in the corners of the infill plate. At cycle 24 (2.4\% drift) plate tears extended to $20 \mathrm{~mm}$ yet no degradation in the strength of the steel plate shear wall was observed. During the final displacement step, which corresponds to $3.9 \%$ drift, large residual buckles became visible at zero drift state, which indicated that the plate had undergone significant plastic elongation (Figure 8). This was the last cycle because it caused a fracture in the beam flange plate at the top of the specimen (Figure 9).

\subsubsection{Specimen SP2}

The cyclic response of Specimen SP2 is shown in Figure 10. The specimen behaved elastically during the first 9 cycles of loading. After this point, some insignificant nonlinear behavior was observed. This nonlinearity occurred due to local buckling of the infill plate. At $1.2 \%$ drift and a base shear of $203 \mathrm{kN}$ (during Cycle 16) the nonlinear behavior became significant. In this specimen no tear in the infill plate was observed but large residual buckling became visible at zero drift, in drifts more than $3 \%$ which indicated that the infill plate had experienced significant plastic elongation. The last cycle underwent at $4.2 \%$ drift because the flange plate near loading point at the top of the specimen failed once more due to fracture.

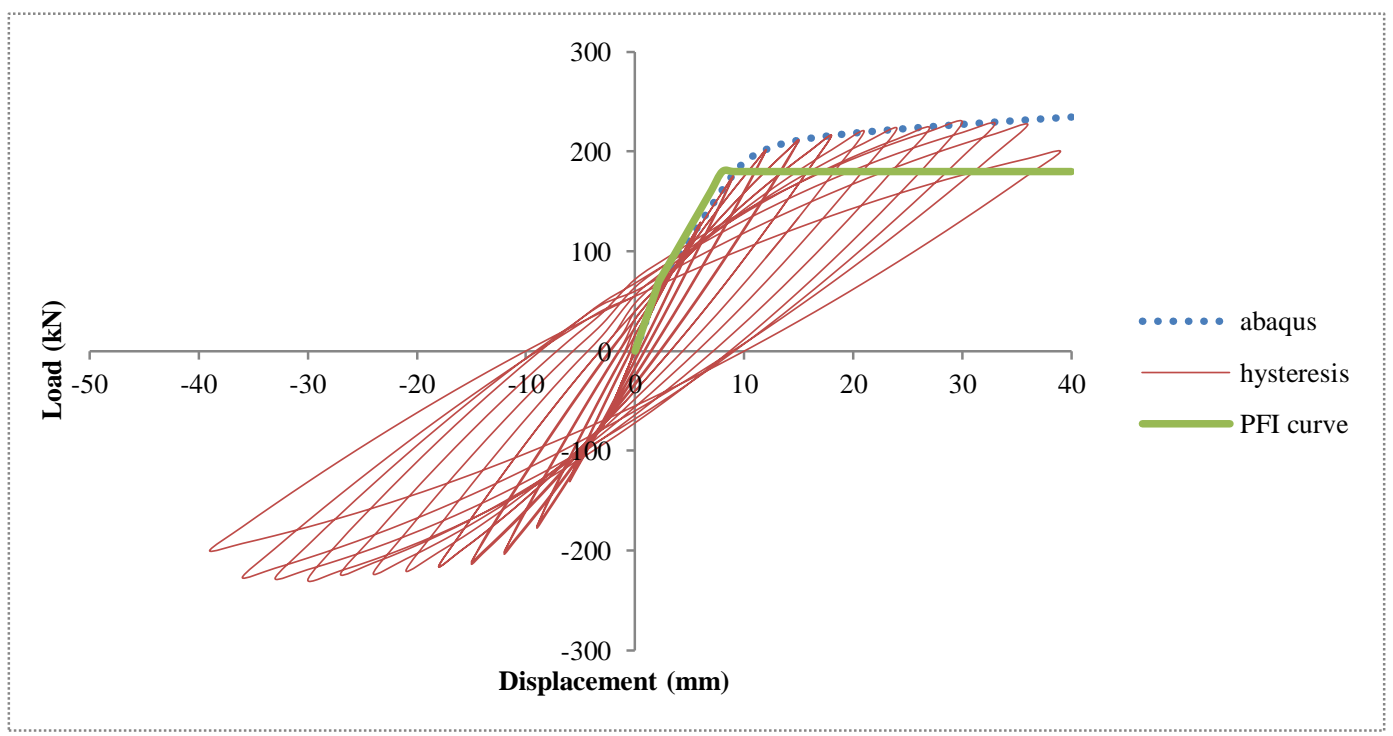

Figure 7. Hysteresis loops of specimen SP1 


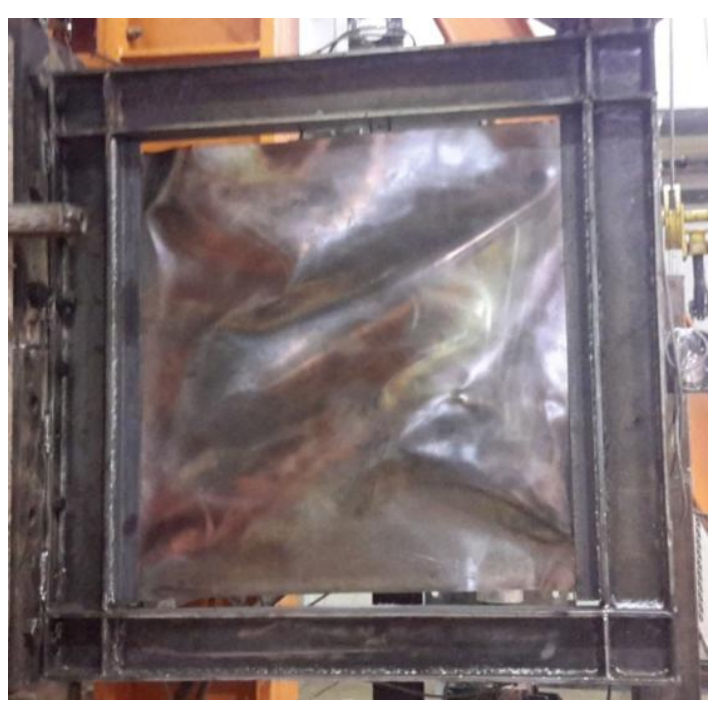

Figure 8. Large Residual buckles at zero drift

\subsubsection{Specimen SP3}

The cyclic response of Specimen SP3 is characterized by the stable hysteretic behavior as shown in Figure11. Specimen SP3 behaved elastically up to a drift of $0.9 \%$, after which the hysteresis loops began to open noticeably. At this drift level, the applied load reached $126 \mathrm{kN}$. The maximum base shear was $193.1 \mathrm{kN}$ and occurred at $3.6 \%$ drift at cycle 28.After the peak base shear strength, degradation began slowly. At the end of the excursions, and at Cycle 30 at $4.2 \%$ drift, the ratio of the base shear related to its maximum value was 0.82 .

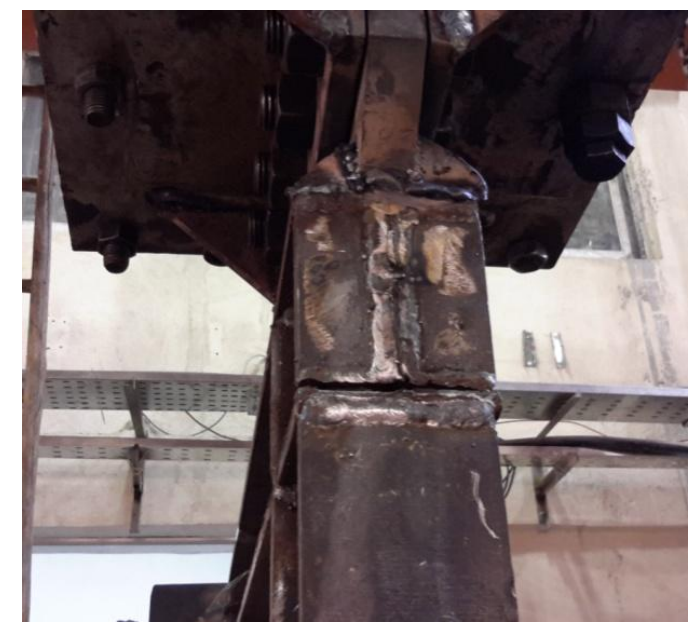

Figure 9. Fracture at flange

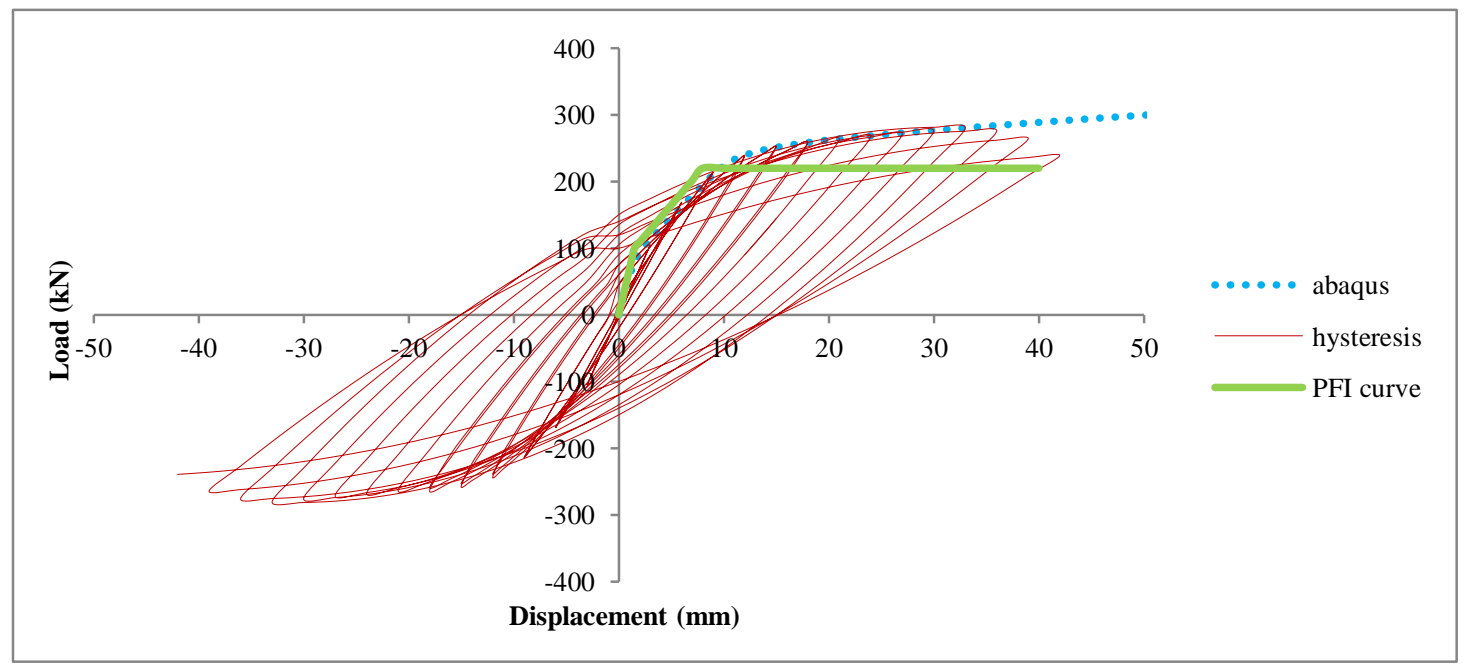

Figure 10. Hysteresis loops of specimen SP2 


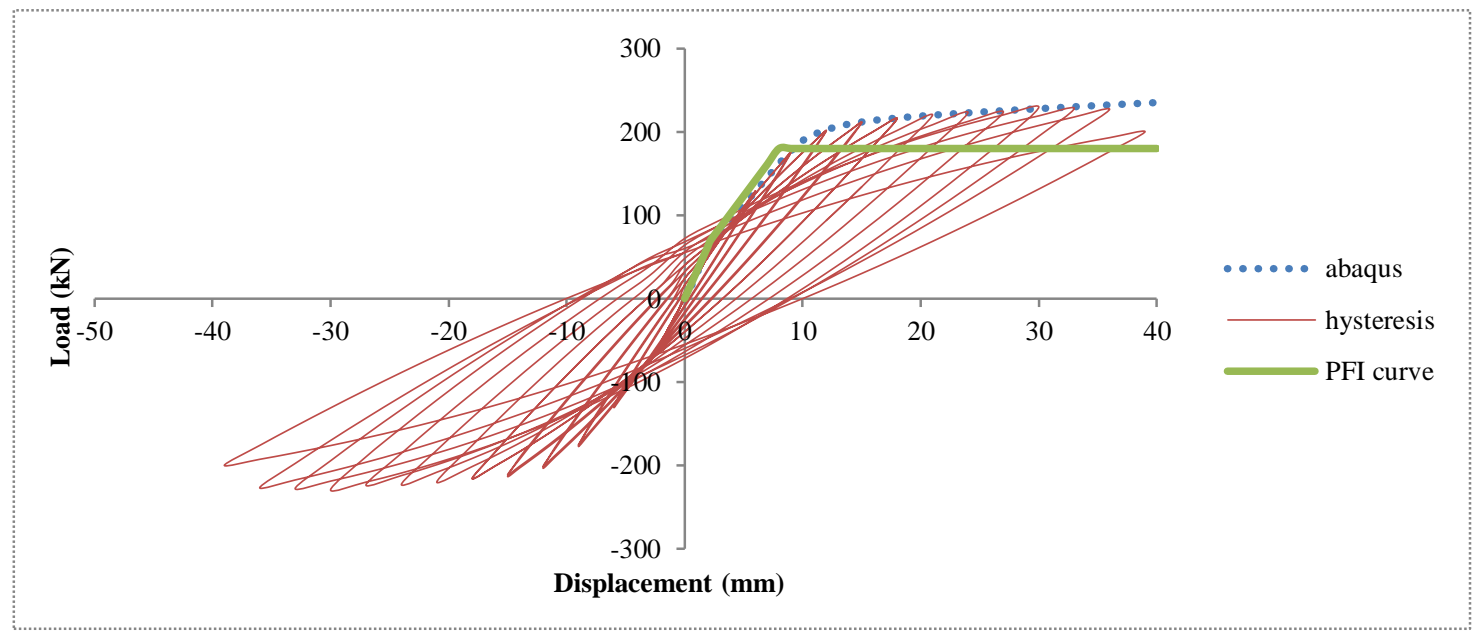

Figure 11. Hysteresis loops of specimen SP3

\subsection{Discussion on Test Results}

Initial stiffness and ultimate strength of the models are key parameters in evaluation the effect of infill plate and its connection to boundary elements on SPSW behaviour. Table 3 shows the maximum strength and initial stiffness of the specimens.

Table 3. Test results

\begin{tabular}{ccccc}
\hline Specimen & Ultimate Load Capacity $(\mathbf{k N})$ & Ratio to bare frame & Initial stiffness $(\mathbf{k N} / \mathbf{m m})$ & Ratio to bare frame \\
\hline SP1 & 231.8 & 1.20 & 29.7 & 1.64 \\
SP2 & 282.4 & 1.46 & 56.6 & 3.13 \\
SP3 & 193.1 & - & 18.1 & - \\
\hline
\end{tabular}

As it is shown in Table 3 the infill plate has a significant effect on ultimate load and initial stiffness of the moment frame. In addition to good hysteresis behaviour of specimen SP1 and SP2, these points establish that using an infill plate will improve behaviours such as ultimate load and stiffness of moment frame system behaviour. However a comparison between SP1 and SP2 indicates that connecting infill plate to both beams and columns will have more gain in ultimate load and initial stiffness. But connecting the infill plate to beams only eliminate the additional tensile forces from the plate acting on columns which will be suitable to reduce the column forces.

\subsection{Comparison of the Experimental Results with Theoretical Equations}

To compare the experimental results with PFI method, a trilinear curve which presents the PFI method is shown in Figures 7, 10 and 11. To determine the curve characteristics Equations 1 to 6 used. To consider the frame stiffness as the beams are not rigid, virtual work method is used. Table 4 presents the properties of the frame and infill plates.

Table 4. Comparison the PFI theory respect to experimental results

\begin{tabular}{ccccccc}
\hline Model & $\begin{array}{c}\text { Experimental } \\
\text { Stiffness }(\mathbf{k N} / \mathbf{m m})\end{array}$ & $\begin{array}{c}\text { PFI theory Stiffness } \\
(\mathbf{k N} / \mathbf{m m})\end{array}$ & $\begin{array}{c}\text { PFI respect to } \\
\text { experimental }\end{array}$ & $\begin{array}{c}\text { Experimental } \\
\text { capacity }(\mathbf{k N})\end{array}$ & $\begin{array}{c}\text { PFI theory capacity } \\
(\mathbf{k N})\end{array}$ & $\begin{array}{c}\text { PFI respect to } \\
\text { experimental }\end{array}$ \\
\hline SP1 & 29.7 & 32.5 & $-9.4 \%$ & 231.8 & 176.7 & $23.8 \%$ \\
SP2 & 56.5 & 65 & $-15.0 \%$ & 282.4 & 212.8 & $24.6 \%$ \\
SP3 & 18.1 & 19 & $-5.0 \%$ & 193.1 & 151.2 & $21.7 \%$ \\
\hline
\end{tabular}

As it is shown PFI method predicts models stiffness fairly accurate but there is some inconsistency in capacity that is because of material hardening which is neglected in PFI method.

\subsection{Energy Dissipation Capacity}

Dissipated energy during loading is one of the important parameters to evaluate a ductile lateral load bearing system. The area under cyclic curve is defined as energy dissipation capacity corresponding to the story shear displacement. The energy dissipation curves of the experimental specimens are shown in Figure 12. 


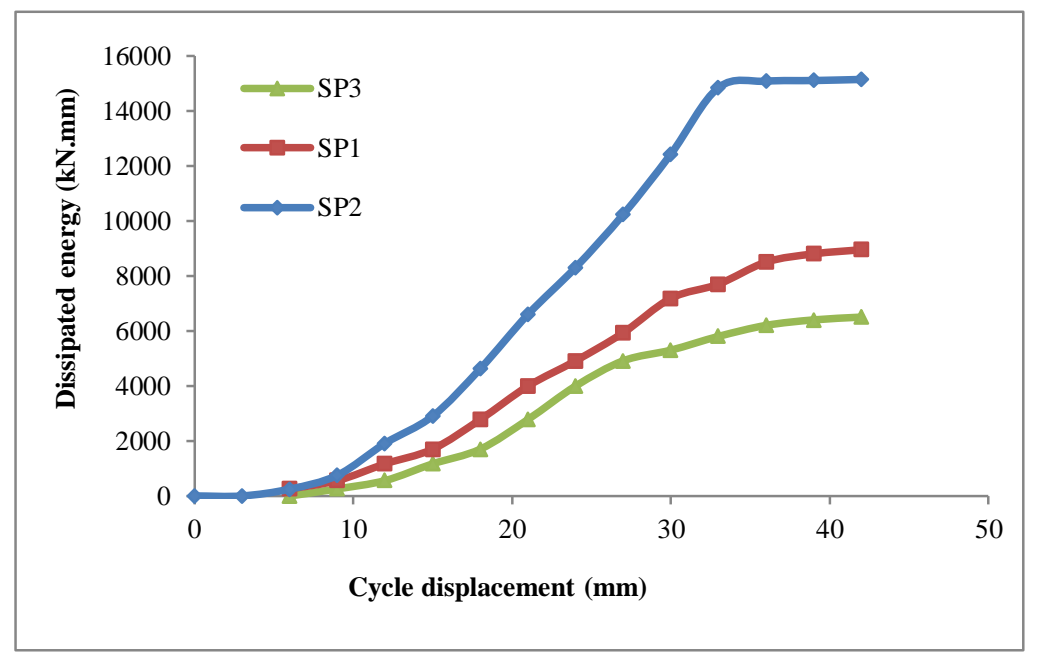

Figure 12. Energy dissipation capacity in specimens

According to this figure, SP2 dissipated more energy than SP1 that is because of partially formation of tension filed in SP1. Yet SP1 dissipated 37\% more energy than SP3.

\section{Numerical Study}

\subsection{Geometric Specifications of Models}

In order to study different parameters such as panel aspect ratio and plate thickness on the behaviour of SPSW with and without connecting the infill plate to columns, a numerical study is done.18 full scale models in this study are considered. Each model consists of one-story one-span moment frame with an infill plate. Span width are assumed 3.5, 5.25 and $7 \mathrm{~m}$. The story height is presumed to be $3.5 \mathrm{~m}$, so the aspect ratio of SPSWs varies from 1 to 2 . Beams are connected to columns through reduced beam section (RBS) moment connection. The column bases is completely restrained in 3 directions. Top of the beams also restrained perpendicular to the frame plane to consider floor effect. The load is applied through displacement at top of columns. In SPSWs the infill plate is fully connected to beams and columns but in DSPSWs the infill plate is just connected to beams.

\subsection{Material Properties}

The ASTM-A36 and ASTM-A572 conventional structural steels are selected respectively for infill plate and frame members. Multilinear elastic-plastic behaviour for materials is assumed and the stress-strain diagrams for both materials (with $\mathrm{E}=200 \mathrm{GPa}$ and $v=0.3$ ) are shown in figure 13. Based on this figure, the yield strength of the infill plate (250 $\mathrm{MPa}$ ) is lower than that of frame members (345 MPa) to let the infill plate yield before frame members and reduce the forces applied by infill plate on VBEs and HBEs.

\subsection{Design Procedure}

Models are designed using seismic provisions for structural steel buildings [23]. The models are designed according to the capacity design principles so that the infill plate is assumed to resist forces corresponding to its expected full shear yield strength. Beams and columns (HBEs and VBEs) are designed to remain elastic while the full yield line is formed in the infill plate. Plastic hinges are only allowed to form at the ends of HBEs.

The primary variables in the analysis are aspect ratio and thickness of plates. The models were categorized in to 3 groups with different aspect ratios (1, 1.5 and 2). In each group 3 different plate thicknesses $(3,5$ and $7 \mathrm{~mm})$ were considered. The specifications of the models are summarized in Table 5. The models in which the infill plates were connected only to beams were denoted as DSPSW. 


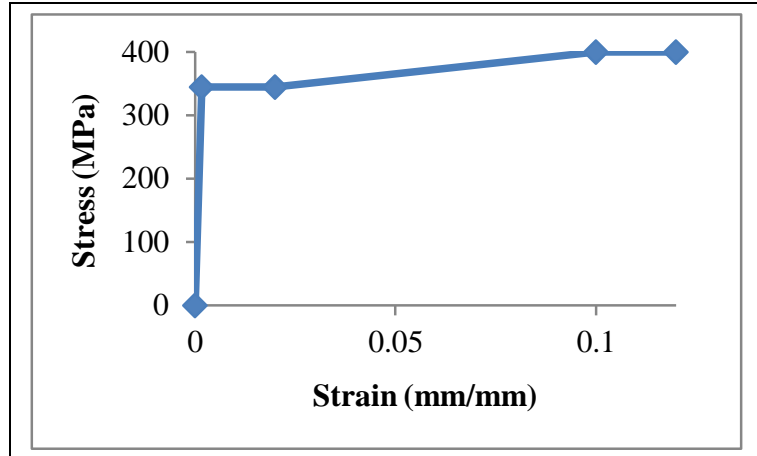

a) Frame members

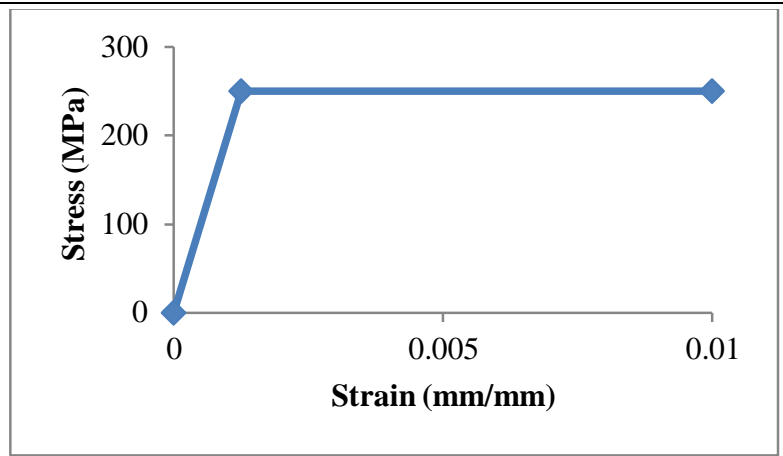

b) Infill wall

Figure 13. Stress-strain diagram

\subsection{Numerical Modeling}

The finite elements analysis is carried out using ABAQUS program. The entire infill plate and boundary elements were meshed using the S4R shell elements, a four node doubly curved general-purpose conventional shell element with reduced integration and hourglass control. Reduced integration together with hourglass control can provide more accurate results, as long as the provided elements are not distorted (relatively close to being square in shape). Using this element significantly reduces running time especially in three dimensional models. Initial imperfections were applied in the models to help initiate panel buckling and development of tension field action. An eigenvalue buckling analysis was first run on the perfect structure to achieve the eigenmodes. Postbuckling analysis was subsequently run after introducing imperfections in the geometry by adding those buckling modes to the perfect geometry where ABAQUS interprets the imperfection data through nodal displacements. Risk analysis was used for determining nonlinear pushover results of the FE model.

To ensure the accuracy a convergence study was carried out to verify the numerical modeling. SP1 FE model was analyzed through different mesh sizes. The results show that $25 \mathrm{~mm}$ mesh size satisfy the accuracy of the analysis. Figure 14 illustrates the convergence study results obtained.

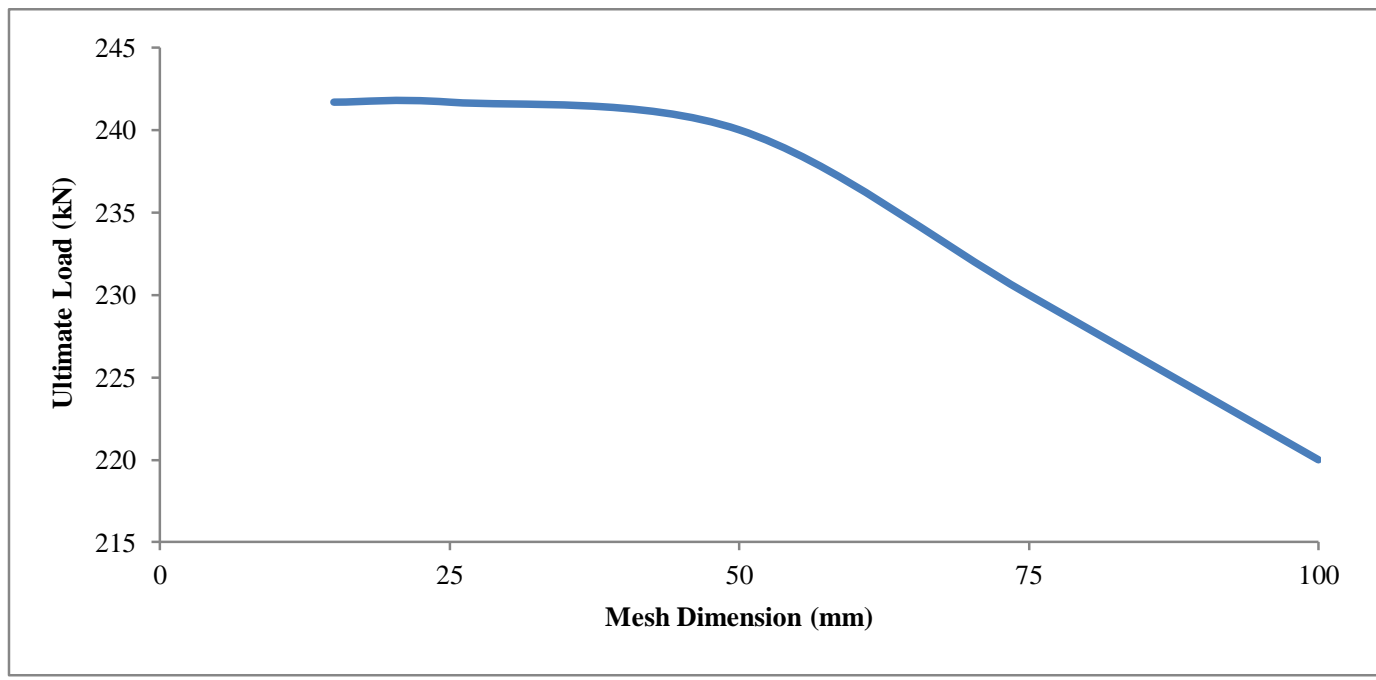

Figure 14. FE mesh size sensitivity

Table 5. Steel plate shear wall specifications

\begin{tabular}{cccccc}
\hline Model & Panel aspect ratio & Connected to column & Column sec. & Beam sec. & Plate thickness (mm) \\
\hline SPSW1-3 & 1 & & & 3 \\
SPSW1-5 & 1 & YES & & 5 \\
SPSW1-7 & 1 & W10x88 & W10x54 & 7 \\
\hline DSPSW1-3 & & & \multirow{2}{*}{ WO $10 \times 54$} & 3 \\
DSPSW1-5 & & & & 5 \\
DSPSW1-7 & & & & 7 \\
\hline
\end{tabular}




\begin{tabular}{|c|c|c|c|c|c|}
\hline SPSW1.5-3 & & & & & 3 \\
\hline SPSW1.5-5 & 1.5 & YES & W10x88 & W10x68 & 5 \\
\hline SPSW1.5-7 & & & & & 7 \\
\hline DSPSW1.5-3 & & & & & 3 \\
\hline DSPSW1.5-5 & 1.5 & NO & W10x88 & W10x68 & 5 \\
\hline DSPSW1.5-7 & & & & & 7 \\
\hline SPSW2-3 & & & & & 3 \\
\hline SPSW2-5 & 2 & YES & W10x88 & W14x74 & 5 \\
\hline SPSW2-7 & & & & & 7 \\
\hline DSPSW2-3 & & & & & 3 \\
\hline DSPSW2-5 & 2 & NO & W10x88 & W14x74 & 5 \\
\hline DSPSW2-7 & & & & & 7 \\
\hline
\end{tabular}

In order to validate the numerical analysis of SPSWs and DSPSWs, the finite element representation using the ABAQUS program has been applied to specimen SP1 and SP2 as mentioned above, and the results compared with the experimental results reported formerly.

As it is shown in Figure 7 and 10, the finite element results are in good agreement with the experimental results. Figure 15 depicts the corresponding stress distribution at the ultimate Load of specimen SP1. As shown, significant plastic deformations have taken place.

It can be seen that stress concentration occurred mostly on the upper right continuity plate which is connected to the loading plate and as mentioned before, fracture happened (Figure 9). Figure 16 represents SP1 infill plate yield lines which are in good agreement with stress distribution presented in Figure 15. As it is shown, incomplete infill plate yielding occurred due to eliminating the connection between infill plate and columns.

Figure 17 represents specimen SP2 stress distribution at the ultimate load and infill plate yield lines, respectively. As it is shown, complete infill plate yielding has occurred due to both beam and column anchorage.

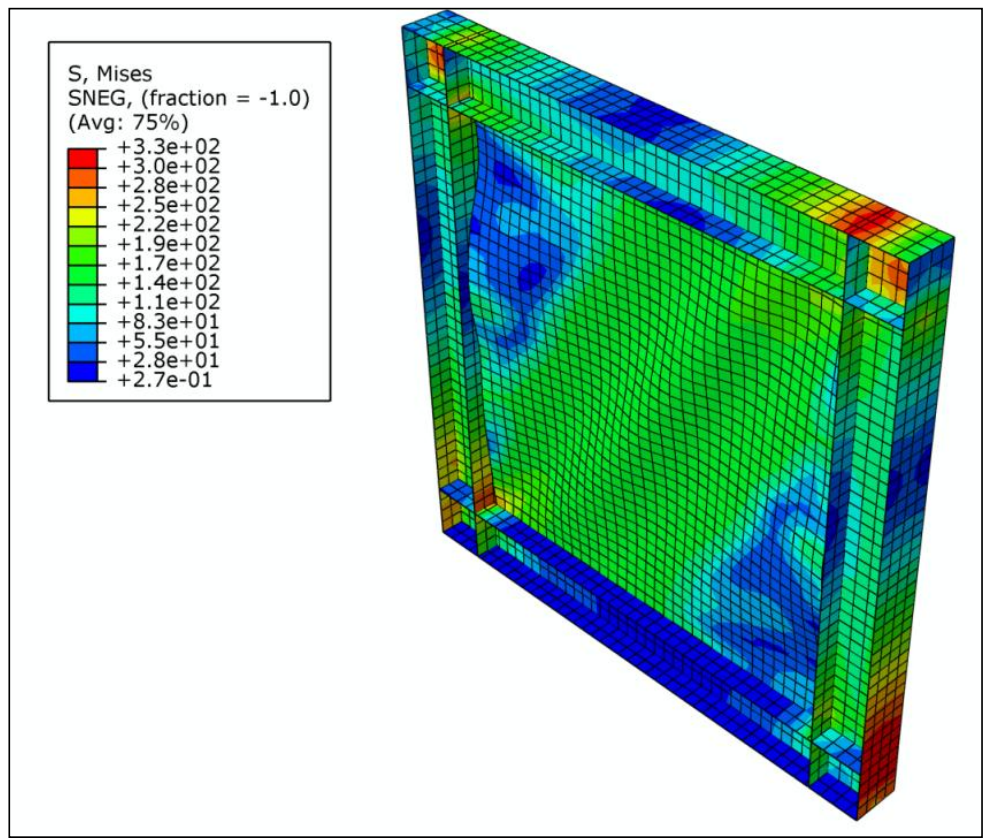

Figure 15. Specimen SP1Stress distribution at ultimate state

\subsection{Numerical Results}

Table 6 presents ultimate capacity and initial stiffness of all models. As it is shown, both capacity and initial stiffness in DSPSWs are decreased in comparison to corresponding SPSW models. Figures 18 and 19 compare ultimate capacity ratio and initial stiffness ratio of DSPSWs to SPSWs versus panel aspect ratio, respectively. Results show that reduction of ultimate capacity and initial stiffness in DSPSWs will decrease as the aspect ratio of models is increased. So using DSPSW in the panels with aspect ratio over 1.5 may be rational. 


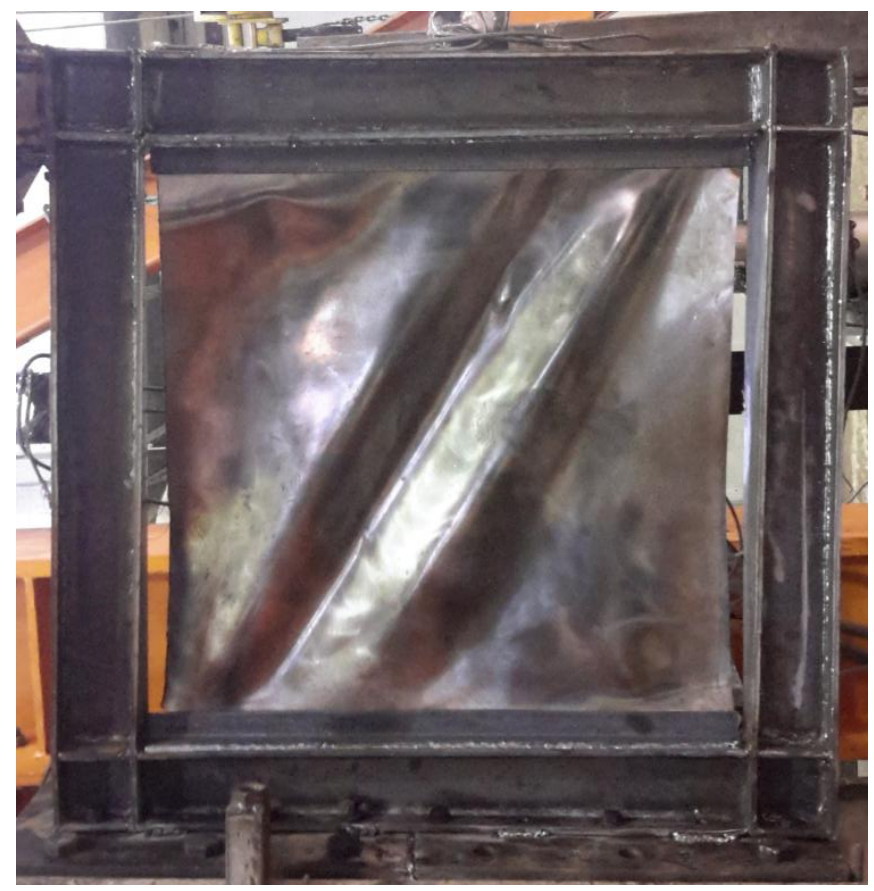

Figure 16. Specimen SP1 infill plate yield lines

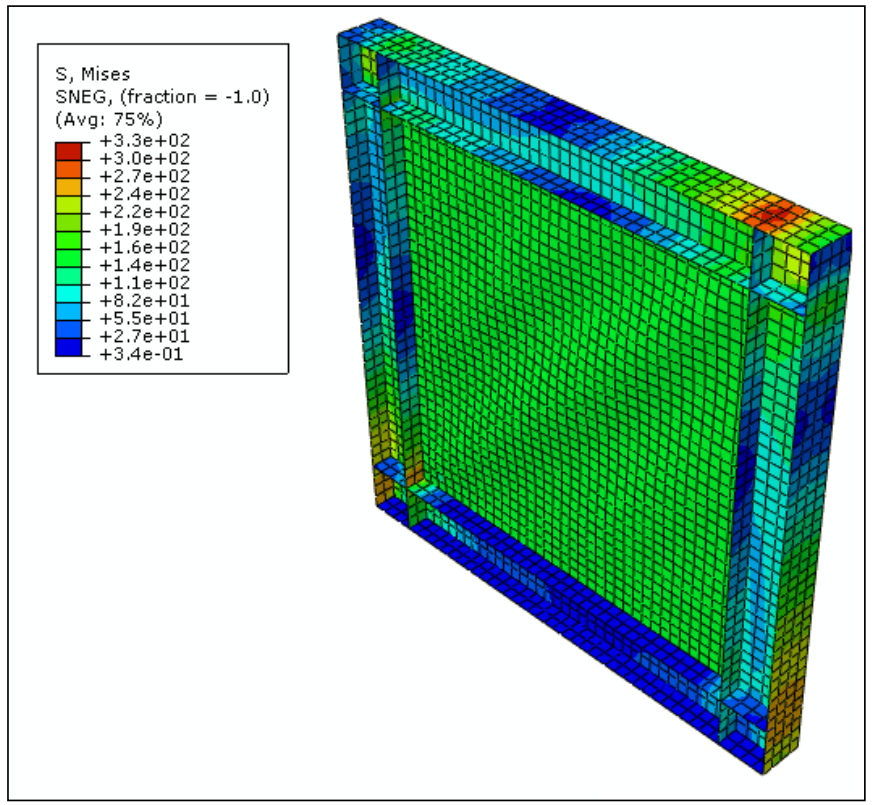

Figure 17. Specimen SP2Stress distribution at ultimate state

A reason which may convince designers to use DSPSW instead of SPSW is eliminating tensile forces in the columns that lead to reducing column demands. Also in cases which available infill plate thickness provide much more capacity relative to demand, detaching the infill plate can provide more economic design reducing forces on boundary elements.

Table 6. Ultimate capacity and initial stiffness of numerical models

\begin{tabular}{ccccc}
\hline Model & $\begin{array}{c}\text { Ultimate capacity } \\
(\mathbf{k N})\end{array}$ & $\begin{array}{c}\text { DSPSW/SPSW } \\
\text { Ultimate capacity }\end{array}$ & $\begin{array}{c}\text { Initial stiffness } \\
(\mathbf{k N / m m})\end{array}$ & $\begin{array}{c}\text { DSPSW/SPSW } \\
\text { Initial Stiffness }\end{array}$ \\
\hline SPSW1-3 & 1251 & & 83 & - \\
SPSW1-5 & 1527 & - & 115 & \\
SPSW1-7 & 1797 & & 176 & 0.663 \\
\hline DSPSW1-3 & 747 & 0.597 & 55 & 0.687 \\
DSPSW1-5 & 883 & 0.578 & 79 & 0.631 \\
DSPSW1-7 & 1018 & 0.567 & 111 & \\
\hline
\end{tabular}




\begin{tabular}{ccccc}
\hline SPSW1.5-3 & 1670 & - & 107 & - \\
SPSW1.5-5 & 2170 & & 176 & \\
SPSW1.5-7 & 2545 & 0.688 & 81 & 0.757 \\
\hline DSPSW1.5-3 & 1149 & 0.660 & 131 & 0.744 \\
DSPSW1.5-5 & 1430 & 0.682 & 179 & 0.758 \\
DSPSW1.5-7 & 1736 & & 126 & - \\
\hline SPSW2-3 & 2031 & - & 204 & \\
SPSW2-5 & 2598 & & 268 & 0.786 \\
SPSW2-7 & 3045 & 0.709 & 99 & 0.730 \\
\hline DSPSW2-3 & 1442 & 0.712 & 149 & 0.750 \\
DSPSW2-5 & 1850 & 0.717 & 201 & \\
DSPSW2-7 & 2182 & & & \\
\hline
\end{tabular}

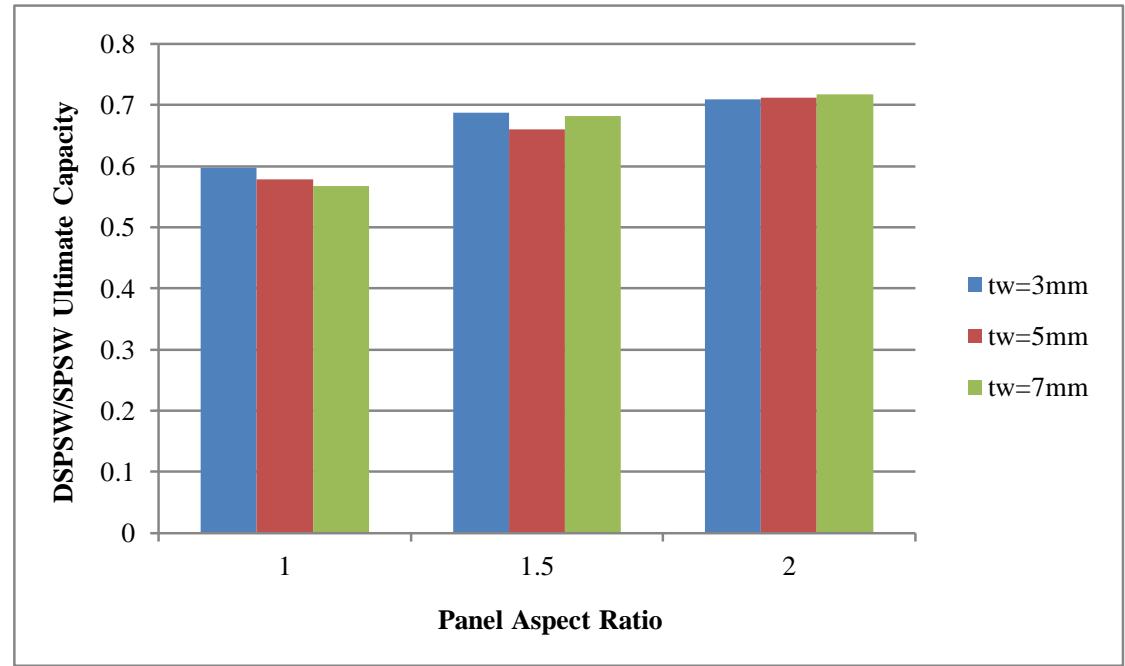

Figure 18. DSPSW/SPSW capacity ratio

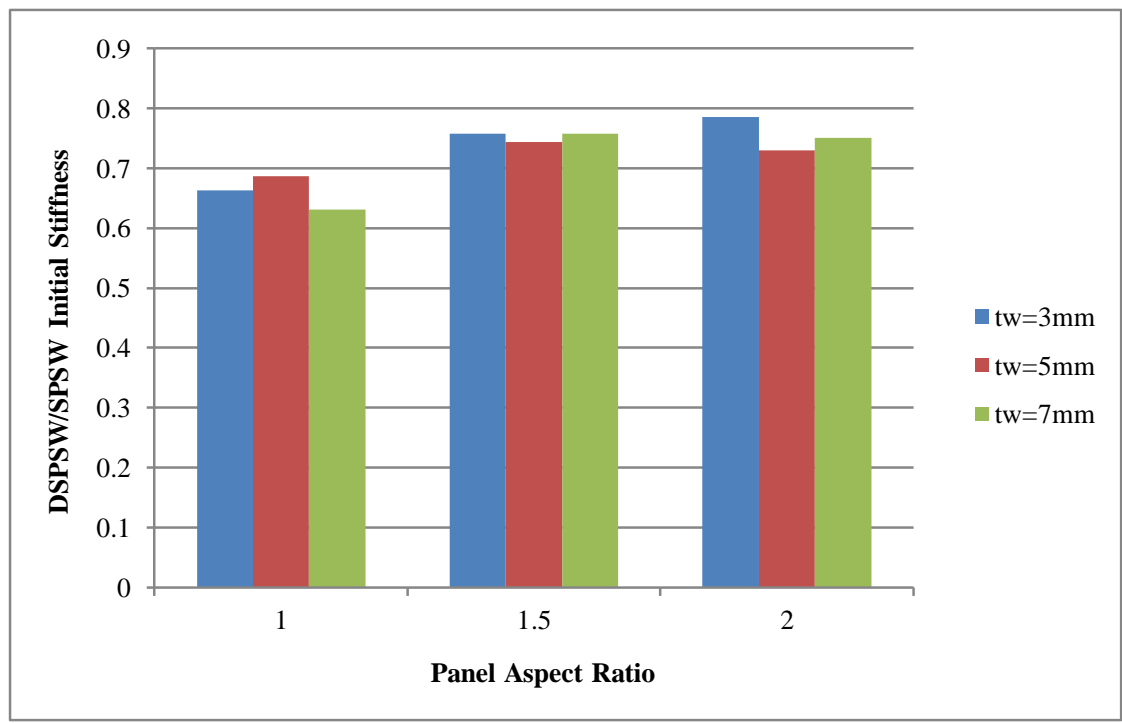

Figure 19. DSPSW/SPSW initial stiffness ratio

\section{Conclusion}

Many previous experimental and analytical studies have shown that the column demands in a SPSW are extremely large. In this research, the effect of eliminating the connection of infill plate and columns is studied to reduce column demands. Also application of PFI theory for related SPSWs is checked, and required relations are presented.

This research included theoretical, experimental and numerical study. Three specimens were tested under quasi static loading and the effect of infill plate and its connection to beam and columns was discussed. As the results indicated using the infill plate will improve the characteristics of the moment frame such as initial stiffness and ultimate load, 
regardless of the type of connection, however connecting the infill plate to both beams and columns will further affect the frame properties. The test results show that eliminating infill plate connection to columns will reduce nearly $20 \%$ of ultimate load, yet SPSWs connecting infill plate to beams only can be used strengthening frame structures not increasing column demands so much.

Numerical results indicate that as the panel aspect ratio increases the reduction in ultimate strength of SPSW due to eliminating the connection of the infill plate to columns will decrease.

\section{References}

[1] Bruneau M, Berman J, Lopez Garcia D, Vian D. "Steel plate shear wall buildings: design requirements and research", North American steel construction conference, Montreal, Canada, April 2005.

[2] Driver RG, Kulak GL, Kennedy DJL ,Elwi AE. "Cyclic test of a four storey steel plate shear wall" ASCE J Struct Eng1998;124(2):112-20. DOI:10.1061/(ASCE)0733-9445(1998)124:2(112).

[3] Berman JW, Bruneau M. "Plastic analysis and design of steel plate shear walls" J Struct Eng ASCE 2003;129(11):1448-56. DOI:10.1061/(ASCE)0733-9445(2003)129:11(1448).

[4] Zhao Q, Astaneh-As 1A. "Cyclic Behavior of Traditional and Innovative Composite Shear Walls" J Struct Eng ASCE 2004;130(2):271-84.DOI: 10.1061/(ASCE)0733-9445(2004)130:2(271).

[5] Qu B, Bruneau M, Lin CH, Tsai KC and Lin YC. "Full scale steel plate shear wall: MCEER/NCREE phase II" tests,Ninth Canadian Conference on Earthquake Engineering Ottawa,Ontario,Canada26-29 June2007.

[6] Caccese V, Elgaaly M, Chen R. Experimental study of thin steel-plate shear walls under cyclic load .J Struct Eng ASCE1993;119(2):573-87.DOI: 10.1061/(ASCE)0733-9445(1993)119:2(573).

[7] Seilie I, Hooper J. "Steel plate shear walls: practical design and construction" Modern Steel Construction 2005(April).

[8] Berman JW. "Seismic behavior of code designed steel plate shear walls" Eng Struct 2011; 33(1): 230-44. 10.1016/j.engstruct.2010.10.015.

[9] Berman JW, Lowes NL, Okazaki T, Bruneau M, Tsai KC, Driver RG, Sabelli R and Moore WP. "Research Needs and Future Directions for Steel Plate Shear Walls". ASCE.

[10] Vian D and Bruneau M. "Steel Plate Shear Walls for Seismic Design and Retrofit of Building Structures" Technical Report MCEER-05-0010, MCEER, Buffalo, NY.

[11] R. Purba, M. Bruneau, "Finite-element investigation and design recommendations forperforated steel plate shear walls" J. Struct. Eng. 135 (11) (2009) 1367-1376.DOI: 10.1061/(ASCE)ST.1943-541X.0000061.

[12] Jahanpour A, Jonsson J and Moharrami H. "Seismic behavior of semi-supported steel shear walls" Journal of constructional steel research,Vol.74, P.118-123, July 2012. DOI: 10.1016/j.jcsr.2012.02.014.

[13]Jahanpour A, Moharrami H and Aghakoochak A. "Evaluation of ultimate capacity of semi-supported steel shear walls" Journal of constructional steel research,Vol.67, P.1022-1030, June 2011. DOI: 10.1016/j.jcsr.2011.01.007.

[14] Borello D, Fahnestock L, "Seismic design and analysis of steel plate shear walls with coupling" J. Struct. Eng. 139 (2013) 12631273. DOI: 10.1061/(ASCE)ST.1943-541X.0000576.

[15] Gholipour M, Asadi E and Alinia MM. "The use of outrigger system in steel plate shear wall structures" Journal of Advances in Structural Engineering 18 (6) (2015): 853-872.

[16] Raisszadeh A.H, Rahai A, Deylami A. "Behaviour of Steel Plate Shear Wall in Multi Span Moment Frame with Various Infill Plate Connection to Column" Civil Engineering Journal, Vol.4 No.1,p.126-137, January 2018.DOI: 10.28991/cej030974.

[17] Choi I.R, and Park H.G. "Steel Plate Shear Walls with Various Infill Plate Designs" Journal of Structural Engineering, Vol. 135, No. 7, July 1, 2009. DOI: 10.1061/(ASCE)0733-9445(2009)135:7(785).

[18] Vatansever C, Yardimci N. Experimental investigation of thin steel plate shear walls with different infill-to-boundary frame connections Steel and Composite Structures, Vol. 11, No. 3 (2011) 251-271. DOI: 10.12989/scs.2011.11.3.251.

[19] Guo L, Rong Q, Ma X, Zhang S, "Behavior of steel plate shear wall connected to frame beams only" Int. J. Steel Struct. 11 (4) (2011) 467-479. DOI: 10.1007/s13296-011-4006-7.

[20] Shekastehband B, Azaraxsh A.A, Showkati H "Experimental seismic study on shear walls with fully-connected and beam-onlyconnected web plates" Journal of Constructional Steel Research 141 (2018) 204-215. DOI: 10.1016/j.jcsr.2017.11.013.

[21] Sabouri-Ghomi S, Ventura CE, Kharrazi MHK. Shear analysis and design of ductile steel plate walls. J Struct Eng (ASCE) 2005;131(6). DOI: 10.1061/(ASCE)0733-9445(2005)131:6(878).

[22] Sabouri-Ghomi S. and Asad Sajjadi, S., " Experimental and theoretical studies of steel shear walls with and without stiffeners ", Journal of constructional steel research,Vol.75, P.52-159, 2012.DOI: 10.1016/j.jcsr.2012.03.018.

[23] AISC, ANSI/AISC 341-10. "Seismic provisions for structural steel buildings". Chicago (IL): American Institute of Steel Construction. 